\title{
Habituating to handling: Factors affecting preorbital gland opening in red deer calves ${ }^{1}$
}

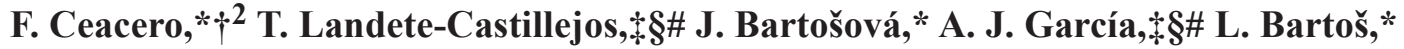 \\ M. Komárková,* and L. Gallegot
}

\begin{abstract}
*Department of Ethology, Institute of Animal Science, Praha 10-Uhříněves, Czech Republic; † Department of Animal Science and Food Processing, Faculty of Tropical AgriSciences, Czech University of Life Sciences. Prague 6-Suchdol, Czech Republic; \$Departamento de Ciencia y Tecnología Agroforestal y Genética, ETSIA, Universidad de Castilla-La Mancha. Albacete, Spain; §Sección de Recursos Cinegéticos, IDR, Universidad de Castilla-La Mancha. Albacete, Spain; and \#Animal Science Techniques Applied to Wildlife Management Research Group, IREC Sec. Albacete. Albacete, Spain
\end{abstract}

ABSTRACT: The preorbital gland plays not only an olfactory role in cervids but also a visual one. Opening this gland is an easy way for the calf to communicate with the mother, indicating hunger/satiety, stress, pain, fear, or excitement. This information can be also useful for farm operators to assess how fast the calves habituate to handling routines and to detect those calves that do not habituate and may suffer chronic stress in the future. Thirty-one calves were subjected to 2 consecutive experiments to clarify if observing preorbital gland opening is related to habituation to handling in red deer calves (Cervus elaphus). Calves were born in 3 different paddocks, handled as newborns (Exp. 1), and then subjected to the same routine handling but with different periodicity: every 1, 2, or 3 wk (Exp. 2). In Exp. 1 , preorbital gland opening was recorded in newborns during an initial handling (including weighing, ear tagging, and sex determination). Preorbital gland opening occurred in $93 \%$ of calves during this procedure and was not affected by sex, time since birth, or birth weight. Experiment 2 consisted of measuring preorbital opening during the same routine handling (weighing, blood sampling, and rump touching to assess body condition) when calves were 1, 3, and 5 mo old. Binary logistic regression showed that gland opening was associated with habituation to handling, since at 1 and 3 mo the probability of opening the gland decreased with the number of handlings that a calf experienced before $(P=$ 0.008 and $P=0.028$, respectively). However, there were no further changes in preorbital gland opening rate in the 5-mo-old calves $(P=0.182)$. The significant influence of the number of previous handlings on the probability of opening the preorbital gland was confirmed through generalized linear model with repeated measures $(P=0.007)$. Preorbital gland opening decreased along the phases of the study. Nevertheless, we found a significant trend in individuals to keep similar opening patterns (intraclass correlation coefficient $=0.807$, $P<0.001$ ), which suggests that the more stressed individuals can be detected with this method. Therefore, we conclude that preorbital gland opening during routine handlings is related to the number of previous handlings, and thus it can be used as an indicator of lack of habituation to handling in farmed cervids.

Key words: calf, Cervus elaphus, habituation, handling routines, preorbital gland, stress

(C) 2014 American Society of Animal Science. All rights reserved.
J. Anim. Sci. 2014.92:4130-4136 doi:10.2527/jas2014-7716

\section{INTRODUCTION}

\footnotetext{
${ }^{1}$ The authors wish to thank Isidoro Cambronero (RIP) and Fulgencio Cebrián for their help with animal handling; Josefa Emilia Lopez-Parra helped with data collection. This study was supported by projects AGL201238898 (Ministry of Economy and Competitiveness, Spain), MZERO0714 (Ministry of Agriculture, Czech Republic), CIGA20145001 (Czech University of Life Sciences, Czech Republic), and IGA no. 20145026 (Faculty of Tropical AgriSciences, Czech Republic).

${ }^{2}$ Corresponding author: francisco.ceacero@outlook.com

Received February 8, 2014.

Accepted June 30, 2014.
}

The preorbital gland has been found in many ungulates, including cervids. It is used mostly for scent marking (Marmazinskaya, 1996; Roberts, 1998; Rajagopal et al., 2011) and by dominant animals during agonistic encounters (Bartoš, 1983). Although most studies have been focused on the olfactory role of this gland in adult animals, some others have also highlighted the important behavioral roles of preorbital gland opening in young in- 


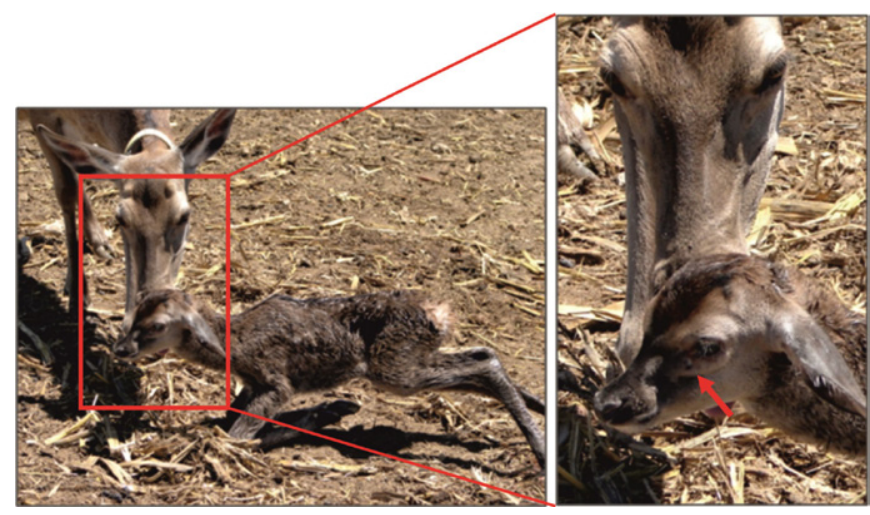

Figure 1. Preorbital gland opening in a newborn calf close to the mother during the first trial to stand up, scarcely $30 \mathrm{~min}$ after delivery. The picture corresponds to a set done from the distance during and after the delivery, without interference in the normal behavior of hind and calf (photo: F. Ceacero). See online version for figure in color.

dividuals. In newborn red deer (Cervus elaphus) calves, it has a primary role in establishing mother-offspring bonds (Hatlapa, 1977), probably since the very beginning (see Fig. 1). This role is mainly associated with hunger (Wölfel, 1976, 1983) and achieving satiety (Bartoš et al., 2005; Bartošová et al., 2012b) but may also serve as stress or excitement indicator both in calves (Bartošová-Víchová et al., 2007) and adult animals (Bartošová et al., 2012a). These recent works also showed a great variability in individual preorbital gland opening (Bartoš et al., 2005; BartošováVíchová et al., 2007; Bartošová et al., 2012a). In adult red deer, Bartošová et al. (2012a) also showed a decrease in the incidence of preorbital gland opening with age both in males and females under a stressful handling, suggesting habituation to repeated handling. However, neither the suggested habituation process nor the factors affecting individual differences in this behavioral response have been studied in red deer calves, although it can be of great interest for assessing animal welfare in farmed cervids.

In the present study we investigated the effects of individual variability and habituation in preorbital gland opening in farmed calves during routine handlings. We expected a decreasing incidence of preorbital gland opening in calves experiencing higher frequency of handlings and tested if this was influenced by sex, weight, body condition, or age of the calf. The consistency of in- dividuals in preorbital gland opening pattern across the whole study period was also studied.

\section{MATERIAL AND METHODS}

This study was performed at the Experimental Farm of Castilla-La Mancha University (Albacete, Spain). The experiment was performed during 2009, involving 31 newborn red deer calves (20 males and 11 females) from hinds aged between 2 and $15 \mathrm{yr}$. All the animals used were born and reared in captivity. The experimental procedure is summarized in the Table 1.

\section{Newborn Experiment}

During the season of births, the farm staff checked the enclosures daily from 0600 to $2200 \mathrm{~h}$ every $2 \mathrm{~h}$ and recorded the date and time of birth. Two of 31 hinds gave birth during the night, so that the middle of the unobserved period $(0200 \mathrm{~h})$ was considered as birth time for calculating the time since birth (hereafter TSB). Red deer calves stay motionless and hidden during their first days of life as antipredatory behavior (Lent, 1974), standing up sporadically to suckle. All the calves tested displayed this behavior during the experiment. Newborn calves were first subjected to the same stressful handling during their first hours of life, which ranged from $1 \mathrm{~h}$ to $6 \mathrm{~d}$ since birth (designed to randomly include variability in TSB). During this experimental procedure, 1 observer recorded the state of the preorbital gland (percentage of time that the gland was open) while the second one handled the calf. The stressful handling treatment consisted in weighing, ear tagging, and sex determination, which are routine procedures with newborns at the farm.

\section{Habituation Experiment}

After birth, calves stayed with their mothers in one of three $10,000-\mathrm{m}^{2}$ enclosures with irrigated pasture and were fed ad libitum with diets based on a recipe suggested by Brelurut et al. (1990). Animals were routinely moved to the handling premises through a 5-m wide corridor for a low-intensity handling. Once there, animals

Table 1. Summary of the experimental procedure

\begin{tabular}{lll}
\hline \hline Parameter & \multicolumn{1}{c}{ Newborn experiment } \\
\hline Age & $0-6 \mathrm{~d}$ & $1 \mathrm{mo} \rightarrow$ Calves accumulate 1 to $4 \mathrm{LIH}^{1}$ \\
& & $3 \mathrm{mo} \rightarrow$ Calves accumulate 3 to $12 \mathrm{LIH}$ \\
& & $5 \mathrm{mo} \rightarrow$ Calves accumulate 5 to $19 \mathrm{LIH}$ \\
Number of calves & $31(20$ male/11 female) & 31 (20 male/11 female) \\
Location & 1 ha pasture paddocks & 2 by 2 by $0.4 \mathrm{~m}$ handling box \\
Handling procedure & Weighing, sex determination, and ear tagging & Weighing, assessment of body condition, blood sampling, and vaccination \\
Duration of handling & Approximately 1 min & Approximately 1 min \\
Preorbital data collected & Opening (Yes/No) and $\%$ of time opened & Opening (Yes/No) and \% of time opened \\
\hline
\end{tabular}

${ }^{1} \mathrm{LIH}=$ low-intensity handlings. 
were weighed and body condition was assessed by rump palpation in a handling box ( $2 \mathrm{~m}$ long by $2 \mathrm{~m}$ tall by 0.4 m wide; see Audigé et al. [1998] and Carrión et al. [2008] for further details). Calves from the different enclosures were subjected to low-intensity handlings (walking to the handling facilities through a wide corridor, weighing without restraining, and slight touching to assess body condition) every 1,2 , or 3 wk $(12,7$, and 12 calves respectively in each group). When calves were around 1 mo old, they all were subjected to a high-intensity handling, which also included blood sampling and vaccination. Weight, body condition, and number of previous handling events were recorded for each calf as well as the percentage of time with the preorbital gland open during the handling. The same high-intensity handling protocol was repeated when animals were 3 and 5 mo old. Since the frequency of handlings is different for each group, the actual number of previous handlings in each experimental phase is different among animals within the same group because it depends on their birth date.

\section{Statistical Analyses}

Analyses were performed in IBM SPSS Statistics version 20 (IBM, New Orchard Road, Armonk, New York 10504). We set out to do an exploratory analysis to detect which factors may affect preorbital gland opening in each experimental phase. The influence of sex, birth weight, body condition, and number of previous handlings on the probability of opening the gland at 1, 3, and 5 mo of age was tested by binary logistic regression (backward Wald method). Nagelkerke's $R^{2}$ was calculated in each analysis, and a Hosmer and Lemeshow test was used as a measure of goodness-of-fit (adequate when the test is not significant). Since nearly all newborns opened the preorbital gland, binary logistic regression would not well discriminate the influence of variables involved in its opening. Therefore, we used linear regression for studying which factors are involved in the time opening the preorbital gland in newborns. Sex, TSB, and birth weight were the variables included in the analysis for newborns.

Then we used a GLM for repeated measures to assess in a more detailed way the effects of the factors that exploratory analysis had revealed to be important. The model included 4 levels corresponding to the 4 experimental phases where data was collected: newborns, first month, third month, and fifth month. In this confirmatory model, the dependent variable was the binary response: whether calves opened the gland or not during each phase. Sex was introduced in the model as factor, and TSB, weight, body condition, and number of previous handlings before $5 \mathrm{mo}$ were introduced as covariates. We selected the measures linked to the fifth month of life because the 3 variables (weight, body condition, and number of previous han- dlings) were correlated with the measures when calves were 1 and 3 mo old; however, the fifth month values showed a greater variability and were more informative.

Finally, to assess whether some individuals remained stressful whereas others habituated well or all responded similarly, we tested for "individuality" effects across the 4 experimental phases. Spearman's rho tests showed this effect through the ranked correlations of the percentage of time opening the preorbital gland during each of the phases. Thereafter, we calculated the repeatability of the occurrence of preorbital gland opening through the intraclass correlation coefficient (ICC), which is a measure of reliability derived from a 1-way ANOVA (Bartko, 1966). This procedure describes the proportion of variance in a character occurring among individuals and can be used as an estimation of the individual repeatability of different observations (Bartoš et al., 2007; Allen-Arave et al., 2008; Stanley and Dunbar, 2013).

\section{RESULTS}

\section{Newborn Experiment}

The experimental procedure was performed with newborn calves within the first days of life $(35.5 \pm$ $5.5 \mathrm{~h}$ ). Handling of newborns lasted for $53.5 \pm 8.3 \mathrm{sec}$, and $93 \%$ of calves opened the preorbital gland in this phase. Shapiro-Wilks normality test showed that the percentage of time opening the gland was not normally distributed. After transformation through arcsine of the squared root, linear regression showed that sex, weight, $\mathrm{TSB}$, and duration of handling did not influence the percentage of time that newborn calves kept the preorbital gland open during the handling.

\section{Habituation Experiment}

The high rate of preorbital gland opening observed in newborns decreased constantly along the habituation experiment $(50 \%$ in the first month test, $39 \%$ in the third month, and $30 \%$ in the fifth). Nevertheless, when preorbital gland opening occurred, it was always with similar intensity since the mean percentage of time with the gland open (considering only those calves that opened) stayed almost constant during the whole experiment (Fig. 2).

Preorbital gland opening was only related to the number of previous handlings when calves were handled at the age of $1 \mathrm{mo}(\beta=-1.171, P=0.008$, Nagelkerke's $R^{2}=0.362$; Hosmer and Lemeshow test was not significant and sex, weight, and body condition were not significant in the model). When handled at the age of 3 mo, preorbital gland opening was also related only to the number of previous handlings $(\beta=-0.778, P=$ 0.028 , Nagelkerke's $R^{2}=0.484$; Hosmer and Lemeshow 


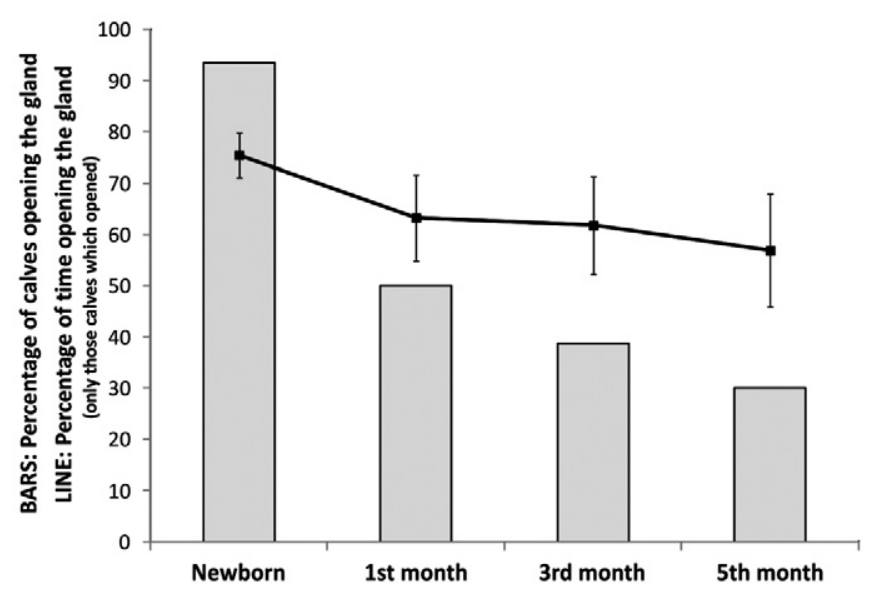

Figure 2. Percentage of calves that opened the preorbital gland during each of the 4 experimental phases (bars), showing a clear and constant decrease. The line indicates the percentage of time that calves had the gland open during the handling, considering only those claves that did it.

test was not significant). However, when calves were handled at 5 mo of age, preorbital gland opening was not related to any studied variable. The probabilities of opening the preorbital gland predicted by the models for each observation are shown in Fig. 3. Since we could not obtain a significant model for the fifth month, we show the predictions for the best model obtained, which also involved only the number of previous handlings $(\beta=$ $-0.143, P=0.182$, Nagelkerke's $R^{2}=0.095$; Hosmer and Lemeshow test was not significant).

Repeated measures GLM confirmed the essential influence of the number of handlings in the habituation process (Table 2). The data did not significantly deviate from sphericity (Mauchly's test: $\mathrm{W}=0.800, P=0.523$ ), and therefore, statistics for assumed sphericity are shown. It only revealed a significant negative interaction between opening and number of previous handlings $(P=0.007)$. The between-subjects differences in preorbital gland opening was also negatively related only to the number of previous handlings $(P=0.002)$. Similarly, the number of previous handlings was the only variable with an overall significant negative effect in the within-subjects variability $(P=0.035)$. Variables significantly affecting preorbital gland opening in the within-subjects model were linked to the first $(\beta=-0.063, t=-2.884, P=0.005)$ and third month $(\beta=-0.063, t=-3.161, P=0.005)$.

\section{Individuality in Preorbital Gland Opening Behavior}

Spearman's rho correlations showed a high consistency in the percentage of preorbital gland opening within individuals, since percentage of time opening the gland in 1 stage was usually related to opening in previous phases (Table 3). That means that those calves that opened the preorbital gland for longer in a given phase also did it in the followingphase.
Table 2. Repeated measures GLM showing variables explaining preorbital gland opening occurrence between and within subjects

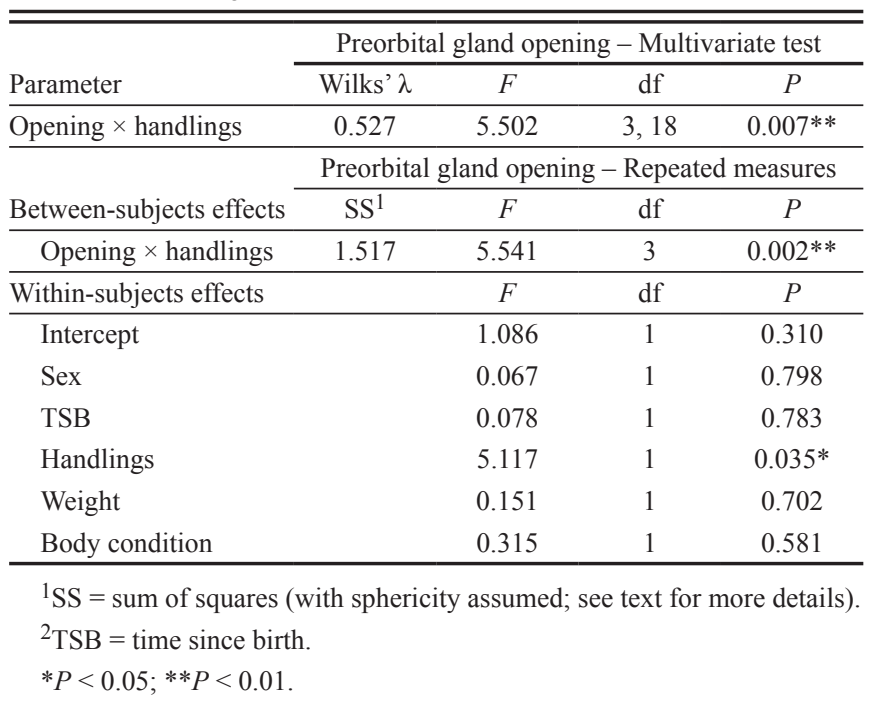

The ICC for the occurrence of preorbital gland opening between the 4 experimental phases was also significant: ICC $=0.639, P<0.001$. Repeatability increased when considering only the habituation experiments (first to fifth month; ICC $=0.807, P<0.001$ ).

\section{DISCUSSION}

Our experimental setting provided evidence that a high frequency of low-stress handlings lead to a fast habituation to routine handling of red deer calves and especially that preorbital gland opening reflects this process of habituation to human handling. Preorbital gland opening is a common behavior among calves when faced with stressful, painful, or exciting situations since the very beginning of their lives, as reported earlier in adult and subadult red deer (Bartošová-Víchová et al., 2007). This stress- or excitement-related behavior (BartošováVíchová et al., 2007; Bartošová et al., 2012a) rapidly decreases when calves are frequently subjected to a lowintensity routine handling. On the other hand, we found a significant individual repeatability in the occurrence of preorbital gland opening across handlings and high ranked correlation of the time opening the gland. That means that those calves that opened in a given phase also did it in the following phase, and those that did it for longer also did it in the following phase. Therefore, a regular assessment of the state of the preorbital gland during routine handling can be used not only as an easy indicator of calf stress but also as an indicator of habituation to routine handling in farmed cervids as previously suggested for adults (Bartošová et al., 2012a), or in other words an indicator of sensitivity to stress, and therefore as a tool to detect those calves that are not ha- 


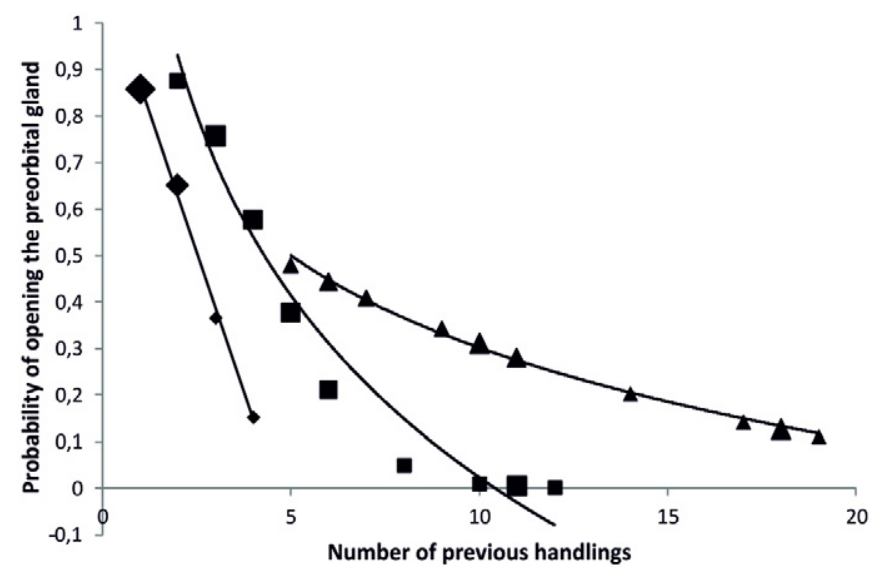

Figure 3. Influence of the number of previous low-intensity handlings on the probability of opening the preorbital gland during stressful handlings when calves are 1 (diamonds), 3 (squares), or 5 mo old (triangles). The probability has been estimated through binary regression models for each particular age of the calf. The size of the marks is equivalent to the number of observations (calves) for each number of previous handlings. The number of previous handlings is a very good predictor of preorbital gland opening in the first month and fairly good in the third month, but this interaction is no longer statistically significant in the fifth month.

bituating and may suffer of chronic stress. Our results also confirm that cervids generally show a successful habituation to farming (Asher et al., 1996).

Mother-offspring recognition and communication can use visual, olfactory, and acoustic cues. Acoustics are efficient both in short and long distances, and therefore they are proposed as a key mechanism especially in hider ungulates (Torriani et al., 2006). Nevertheless, acoustic cues can be also a serious risk because of attacks by predators or even other hinds (Kelly and Whateley, 1975). Therefore, the preorbital gland seems especially important for deer communication because it may play both visual and olfactory roles in the establishment of mother-offspring bonds (Hatlapa, 1977). The preorbital gland contains volatile substances that give information about the individual and about age (different profile between adults and immature animals; Lawson et al., 2000, 2001). Until now, no study has documented when this volatile secretion is initially produced (a dark yellow exudate is clearly visible in adult animals but not in calves), and moreover, other cervids such as fallow deer has no such volatiles in the secretion (Lawson et al., 2000, 2001). Therefore, we may expect that the visual role of preorbital gland opening in young calves seems to be more important than the olfactory one. Whether it has the visual or the olfactory role during stressful handling still remains to be studied. Nevertheless, it is clearly a signal of fear or stress to the mother, and therefore, our results confirm that it can be used by farm operators as a signal of stress, as previously proposed in newborn calves (Bartošová-Víchová et al., 2007).

Why do calves show stronger fear response (preorbital gland opening) in the first months and thereafter this response disappears? Animals, including cervids, perceive human disturbance in a way similar to predation risk (see Li et al. [2007] and references therein). This was also demonstrated for red deer calves (Bartošová-Víchová et al., 2007). A potential danger activates brain pathways that mediate alert and defensive behaviors linked to fear or anxiety, and these behaviors can be unlearned (as the observed preorbital gland opening in newborns) but also experience dependent (Wiedenmayer, 2009; as the observed preorbital gland opening in our "habituation experiment"). The reactions of each animal will be ruled by a complex interaction between genetic factors (individuality) and previous experience (Grandin, 1997). Livestock habituate to light routine procedures such as weighing or even blood sampling (Alam and Dobson, 1986; Grandin, 1989; Hutson, 1993) but not to hard ones that generate great aversion (Hargreaves and Hutson, 1990). The habituation to familiar human handlers is also an important factor demonstrated from rats (Davis et al., 1997) to cows (Boivin et al., 1998). Similar results have been obtained with wild species such as giraffe (habituation to restraining: Wienker, 1986), Persian fallow deer (lower corticosteroids in feces of animals with high contact with humans; Zidon et al., 2009), Chinese water deer (lower cortisol levels in hand reared calves; Hastings et al., 1992), or red deer (fast habituation from wild to farming conditions [Goddard et al., 1996], habituation by calves to alarm stimulus [Espmark and Langvatn, 1985], or habituation to repeated handling [Diverio et al., 1993]).

Regarding preorbital gland opening, which seems to be similarly expressed as other behaviors linked to stress, its incidence during handling decrease with age in adults red deer of both sexes (Bartošová et al., 2012a).

Table 3. Spearman's rho $(\rho)$ showing the ranked correlation in percentage of preorbital gland opening among the different stressful experimental procedures

\begin{tabular}{|c|c|c|c|c|c|c|c|c|c|}
\hline \multirow[b]{2}{*}{ Parameter } & \multicolumn{3}{|c|}{ First month } & \multicolumn{3}{|c|}{ Third month } & \multicolumn{3}{|c|}{ Fifth month } \\
\hline & $\rho$ & $P$-value & $n$ & $\rho$ & $P$-value & $n$ & $\rho$ & $P$-value & $n$ \\
\hline Newborns & -0.04 & $0.837^{\mathrm{NS}}$ & 27 & 0.41 & $0.030 *$ & 28 & 0.61 & $<0.001 * * *$ & 27 \\
\hline First month & & & & 0.63 & $<0.001 * * *$ & 30 & 0.17 & $0.388^{\mathrm{NS}}$ & 29 \\
\hline Third month & & & & & & & 0.64 & $<0.001 * * *$ & 30 \\
\hline
\end{tabular}

NS non-significant.

$* \mathrm{P}<0.05 ; * * * \mathrm{P}<0.005 ; \mathrm{NS}=$ not significant. 
Our results clearly show that number of previous handlings more than age explains this habituation process, with small influence of weight in younger calves probably related to differences in physical development as it happen also with the occurrence of fleeing response (Kelly and Whateley, 1975; Espmark and Langvatn, 1985). This effect of the number of previous handlings disappeared in the last handling when calves were 5 mo old, which probably reflects that successful habituation to handling occurs during the first months of life but no longer than 5 mo. High frequency of low-intensity handlings during the first months lead to a faster decrease in the rate of preorbital gland opening in further handling or during a more stressful procedure such as blood sampling. This handling schedule (better weekly than quarterly, etc.) seems therefore adequate to reduce chronic stress in farmed deer, and those not habituated calves can be detected through preorbital gland opening behavior when aged 5 mo old. In fact, $27.6 \%$ of adult red deer hinds opened the gland during routine handlings in an experimental farm (Prague, Czech Republic) where number of handlings is rarely more than 5 per yr (Bartošová et al., 2012a), while in the experimental farm where this study was conducted (Albacete, Spain), where handlings can reach 52 per yr, a similar preliminary test with 103 adult hind showed an opening rate of only $8.7 \%$ (unpublished data).

Finally, results show great individual differences in preorbital gland opening. There is a significant repeatability both in the occurrence of this behavior and in the time that each animal display it during the 4 experimental procedures, and this within-subjects variance can be hardly explained by any variable. Those calves that opened for longer as newborns also did it during routine handling at 1 , 3 , and $5 \mathrm{mo}$. Moreover, the probability of opening during each handling was usually explained only by the number of previous handlings and by the percentage of time that they opened the gland during previous handlings. Bartoš et al. (2005) found a large range of individual responses in preorbital opening in calves related to feeding (both before and after the meal). Bartošová-Víchová et al. (2007) and Bartošová et al. (2012a) found similar consistency pattern related to stressful events. Previous studies with red deer also showed that while most animals habituate well to handling, some individuals totally fail to adapt (Asher et al., 1996). Pollard and Littlejohn (1995) also found a repeated avoiding behavior to humans on an individual basis. Finally, Chaya et al. (2006) showed consistency in individual responses against handling both in calves and hinds.

In conclusion, our results highlight 1) the positive influence of a constant low-stressful handling routine to improve the habituation to handling of the whole herd and 2) the adequacy of preorbital gland opening to detect early those animals that (probably because of a genetic predisposition) will hardly fully habituate to repeated handling and therefore may suffer of chronic stress. Future research may focus on the influence of individuality and genotype in the occurrence of preorbital gland opening behavior.

\section{LITERATURE CITED}

Alam, M. G. S., and H. Dobson. 1986. Effect of various veterinary procedures on plasma concentrations of cortisol, luteinizing hormone and prostaglandin E2 metabolite in the cow. Vet. Rec. 118:7-10.

Allen-Arave, W., M. Gurven, and K. Hill. 2008. Reciprocal altruism, rather than kin selection, maintains nepotistic food transfers on an Ache reservation. Evol. Hum. Behav. 29:305-318.

Asher, G. W., M. W. Fisher, and P. F. Fennessy. 1996. Environmental constraints on reproductive performance of farmed deer. Anim. Reprod. Sci. 42:35-44.

Audigé, L., P. R. Wilson, and R. S. Morris. 1998. A body condition score system and its use for farmed red deer hinds. N. Z. J. Agric. Res. 41:545-553.

Bartko, J. J. 1966. The intraclass correlation coefficient as a measure of reliability. Psychol. Rep. 19:3-11.

Bartoš, L. 1983. Some observations on the relationships between preorbital gland opening and social interactions in red deer. Aggress. Behav. 9:59-67.

Bartoš, L., R. Bahbouh, and M. Vach. 2007. Repeatability of size and fluctuating asymmetry of antler characteristics in red deer (Cervus elaphus) during ontogeny. Biol. J. Linn. Soc. Lond. 91:215-226.

Bartoš, L., J. Víchová, and J. Lancingerová. 2005. Preorbital gland opening in red deer (Cervus elaphus) calves: Signal of hunger? J. Anim. Sci. 83:124-129.

Bartošová, J., L. Bartoš, R. Kotrba, and F. Ceacero. 2012a. Preorbital opening in farmed red deer (Cervus elaphus) during stressful handling. J. Anim. Sci. 90:3200-3206.

Bartošová, J., F. Ceacero, and L. Bartoš. 2012b. Pre-orbital gland opening: Part of suckling behaviour in red deer (Cervus elaphus) calves. J. Anim. Sci. 90:3207-3212.

Bartošová-Víchová, J., L. Bartoš, and L. Švecová. 2007. Technical note: Preorbital gland opening in red deer (Cervus elaphus) calves as an indicator of stress. J. Anim. Sci. 85:494-496.

Boivin, X., J. P. Garel, A. Mante, and P. Le Neindre. 1998. Beef calves react differently to different handlers according to the test situation and their previous interactions with their caretaker. Appl. Anim. Behav. Sci. 55:245-257.

Brelurut, A., A. Pingard, and M. Thériez. 1990. Le cerf et son élevage. (In French.) INRA, Paris, France.

Carrión, D., A. J. García, E. Gaspar-López, T. Landete-Castillejos, and L. Gallego. 2008. Development of body condition in hinds of Iberian red deer during gestation and its effects on calf birth weight and milk production. J. Exp. Zool. 309A:1-10.

Chaya, W., J. Pollard, and R. Littlejohn. 2006. A note on stability of behavioural reactions to handling in red deer hinds and their calves. Appl. Anim. Behav. Sci. 101:177-182.

Davis, H., A. Taylor, and C. Norris. 1997. Preference for familiar humans by rats. Psychon. Bull. Rev. 4:118-120.

Diverio, S., P. J. Goddard, I. J. Gordon, and D. A. Elston. 1993. The effect of management practices on stress in farmed red deer (Cervus elaphus) and its modulation by long-acting neuroleptics: Behavioral-responses. Appl. Anim. Behav. Sci. 36:363-376.

Espmark, Y., and R. Langvatn. 1985. Development and habituation of cardiac and behavioral responses in young red deer calves (Cervus elaphus) exposed to alarm stimuli. J. Mammal. 66:702-711. 
Goddard, P. J., I. J. Gordon, and W. J. Hamilton. 1996. The effect of post-capture management strategy on the welfare and productivity of wild red deer (Cervus elaphus) hinds introduced to farming systems. Anim. Sci. 63:315-327.

Grandin, T. 1989. Voluntary acceptance of restraint by sheep. Appl. Anim. Behav. Sci. 23:257-261.

Grandin, T. 1997. Assessment of stress during handling and transport. J. Anim. Sci. 75:249-257.

Hargreaves, A. L., and G. D. Hutson. 1990. Some effects of repeated handling on stress responses in sheep. Appl. Anim. Behav. Sci. 26:253-265.

Hastings, B. E., D. E. Abbott, and L. M. George. 1992. Stress factors influencing plasma cortisol levels and adrenal weights in Chinese water deer (Hydropotes inermis). Res. Vet. Sci. 53:375-380.

Hatlapa, H. H. 1977. Zur biologischen Bedeutung des Präorbitalorgans beim Rotwild, Prägung, Individualgeruch, Orientierung. (In German.) Berl. Münch. Tierärtzl. Wochenschr. 90:100-104.

Hutson, G. D. 1993. Behavioral principles of sheep handling. In: T. Grandin, editor, Livestock handling and transport. CAB International, Wallingford, Oxon, UK.

Kelly, R. W., and J. A. Whateley. 1975. Observations on the calving of red deer (Cervus elaphus) run in confined areas. Appl. Anim. Ethol. 1:293-300.

Lawson, R. E., R. J. Putman, and A. H. Fielding. 2000. Individual signatures in scent gland secretions of Eurasian deer. J. Zool. 251:399-410.

Lawson, R. E., R. J. Putman, and A. H. Fielding. 2001. Chemical communication in Eurasian deer (Cervidae): Do individual odours also code for attributes? J. Zool. (Lond.) 253:91-99.

Lent, P. C. 1974. Mother-infant relationships in ungulates. In: V. Geist and F. Walther, editors, The behaviour of ungulates and its relation to management, vol. I. 'International Union for Conservation of Nature publication no. 24. Morges, Switzerland. p. 14-55.
Li, C., Z. Jiang, S. Tang, and Y. Zeng. 2007. Evidence of effects of human disturbance on alert response in Pere David's deer (Elaphurus davidianus). Zoo Biol. 26:461-470.

Marmazinskaya, N. V. 1996. Territorial and marking behaviour of Persian gazelle Gazella subgutturosa (Artyodactyla, Bovidae) at the Bukhara ecological center. Zoologicheskii zhurnal 75:1737-1751.

Pollard, J. C., and R. P. Littlejohn. 1995. Consistency in avoidance of humans red deer. Appl. Anim. Behav. Sci. 45:301-308.

Rajagopal, T., A. Manimozhi, and G. Archunan. 2011. Diurnal variation in preorbital gland scent marking behaviour of captive male Indian Blackbuck (Antelope cervicapra L.) and its territorial significance. Biol. Rhythm Res. 42:27-38.

Roberts, S. C. 1998. Behavioural responses to scent marks of increasing age in klipspringer Oreotragus oreotragus. Ethology 104:585-592.

Stanley, C. R., and R. I. M. Dunbar. 2013. Consistent social structure and optimal clique size revealed by social network analysis of feral goats, Capra hircus. Anim. Behav. 85:771-779.

Torriani, M. V. G., E. Vannoni, and A. G. McElligott. 2006. Motheryoung recognition in an ungulate hider species: A unidirectional process. Am. Nat. 168:412-420.

Wiedenmayer, C. P. 2009. Plasticity of defensive behavior and fear in early development. Neurosci. Biobehav. Rev. 33:432-441.

Wienker, W. R. 1986. Giraffe squeeze cage procedures. Zoo Biol. 5:371-377.

Wölfel, H. 1976. Vorläufiger Bericht über einige neue Beobachtungen zur muterlosen Aufzucht des Rothirsches (Cervus elaphus). (In German.) Z. d. Kölner Zoo 19:16-19.

Wölfel, H. 1983. Juvenile development, mother-child bond and enemy evasion in red deer (Cervus elaphus).2. Z. Jagdwiss. 29:197-213.

Zidon, R., D. Saltz, L. S. Shore, and U. Motro. 2009. Behavioral changes, stress, and survival following reintroduction of Persian fallow deer from two breeding facilities. Conserv. Biol. 23:1026-1035. 